\title{
Prehistoria de la matemática y mente moderna: pensamiento matemático y recursividad en el Paleolítico franco-cantábrico
}

\section{Francisco A. González Redondo (*), Manuel Martín-Loeches (**) y Enrique Silván Pobes $\left({ }^{* * *}\right)$}

\author{
(*) Departamento de Álgebra, Universidad Complutense de Madrid (UCM) faglezr@edu.ucm.es \\ (**) Departamento de Psicobiología, UCM \\ $(* *)$ Departamento de Didáctica de las Ciencias Experimentales, UCM
}

Dynamis

[0211-9536] 2010; 30: 167-195
Fecha de recepción: 14 de diciembre de 2009

Fecha de aceptación: 22 de febrero de 2010

SUMARIO: 1.-El soporte material del pensamiento simbólico. 2.-Registro simbólico e historia de la matemática. 2.1.—La visión estándar en historia de la matemática. 2.2.—Hacia el registro del tiempo: la cota Marshack. 2.3.-Contabilidad en el Paleolítico africano: la conjetura Zaslavsky. 2.4.-Matemática implícita en el mobiliar europeo. 3.-El registro del pensamiento matemático en el mobiliar de la región franco-cantábrica. 4.-Altamira: culminación en el registro mobiliar del pensamiento matemático.

RESUMEN: En este artículo, en primer lugar, se repasan de forma general distintos tipos de registros simbólicos realizados por los grupos prehistóricos desde los más remotos y probables orígenes de la mente humana moderna. A continuación, se revisan algunas de las más destacadas piezas de la Prehistoria relacionadas con el registro matemático, destacando la importancia (por cantidad y calidad), no suficientemente valorada, de las piezas de este tipo de la región franco-cantábrica. La información anterior, finalmente, nos da pie a destacar la tremenda importancia en este contexto de cuatro plaquitas de hueso hioides de caballo de la Cueva de Altamira, datadas en el Solutrense Superior (c. 18.500 años). Estas plaquitas, al ser un conjunto coherente de elementos interrelacionados, se proponen aquí como la representación de una recursividad, cualidad ésta que se ha considerado como propia y exclusiva del lenguaje humano.

PALABRAS CLAVE: Matemática, Paleolítico, Prehistoria, pensamiento, recursividad.

KEY WORDS: Mathematics, Paleolithic, Prehistory, recursion, thought. 


\section{El soporte material del pensamiento matemático}

A grandes rasgos, parece que la mente humana actual, al menos en sus principales características y por sus manifestaciones y registros contrastables, pudo tener su origen un tiempo después del surgimiento de nuestra especie desde el punto de vista anatómico. Si éste último se podría remontar a 200.000 $\mathrm{BP}$, el advenimiento de una mente plenamente moderna parece que tuvo que esperar un tiempo, discutiéndose actualmente si surgió en África hace unos 100.000 años o si aún hubimos de esperar a su surgimiento en Europa hace apenas $40.000^{1}$. Lo que sí parece estar claro, por las características de las herramientas y otros parámetros, es que en el momento en el que situamos el origen de nuestra especie por sus características anatómicas, nuestras capacidades cognitivas no debieron ser muy distintas de las del hombre de Neandertal.

Entre esos parámetros que, además de las herramientas, nos permiten decidir si estamos o no ante una mente moderna, se encuentran diversos tipos de manifestaciones que han quedado registradas ${ }^{2}$, tales como el arte figurativo, las inhumaciones con aparato funerario, el adorno corporal, los instrumentos musicales, o las marcas (lineales, puntuadas, etc.) dejadas deliberadamente sobre diversos tipos de materiales, entre los que abundan los líticos y, sobre todo, los óseos. Es a éste último grupo de manifestaciones, muchas veces conocidas como «marcas de caza», a las que pertenecen los que probablemente sean los primeros registros contables de la historia de la humanidad.

En este punto conviene hacer una advertencia, ya que ni todas las marcas dejadas por seres humanos hace decenas de miles de años son deliberadas, ni todas las que son deliberadas tienen por qué representar registros contables. A este respecto, nos vamos encontrar con enconados debates dentro de la literatura científica ${ }^{3}$. En principio, podemos decir que

1. Coolidge, Frederick L.; Wynn, Thomas. The rise of homo sapiens: the evolution of modern thinking. Oxford: Wiley-Blackwell; 2009. Martín-Loeches, Manuel. La mente del Homo sapiens. Madrid: Aguilar; 2008.

2. Balari, Sergio; Benítez Burraco, Antonio; Camps, Marta; Longa, Víctor M.; Lorenzo, Guillermo; Uriagereka, Juan. ¿Homo loquens neanderthalensis? En torno a las capacidades simbólicas y lingüísticas del Neandertal. Munibe Antropologia-Arkeologia. 2008; 59: 3-24.

3. Barandiarán, Ignacio. Imágenes y adornos en el arte portátil paleolítico. Barcelona: Ariel; 2006. En este trabajo priorizaremos la valoración del contenido matemático implícito en la decoración de las piezas más que su estudio arqueológico, que puede verse en la literatura. 
la mayoría de los autores no consideran marcas deliberadas sobre material lítico u óseo aquellas dejadas por otra especie que no sea la nuestra.

Es cierto que existen algunos hallazgos, como los de la cueva de Kozarnika (Bulgaria) (figura 1), dejados por Neandertales, consistentes en placas de hueso con diversas muescas lineales. Sin embargo, el consenso más generalizado es que este tipo de hallazgos fueron fruto de una situación fortuita y no deliberada, como es la de descarnar el hueso con una herramienta lítica ${ }^{4}$.

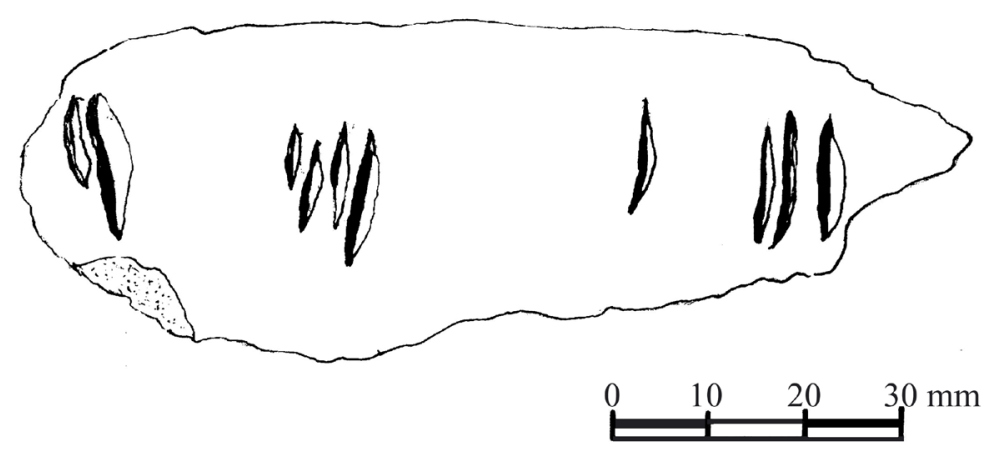

Figura 1. Placa de Kozarnika.

La supuesta flauta Neandertal de la cueva de Divje Babe, en Eslovenia, es otro ejemplo similar de este tipo de situaciones, ya que un estudio exhaustivo y pormenorizado de este objeto ha determinado su origen fortuito, de manera que los dos orificios alineados que nos hacen creer que nos hallamos ante un instrumento musical han resultado ser las huellas de los incisivos de un carnívoro ${ }^{5}$. En la misma situación se encuentran otros presuntos registros de lo que hoy llamamos arte dejados por especies distintas a la nuestra.

4. Mithen, Stephen J. The singing Neanderthals: the origins of music, language, mind and body. Cambridge: Harvard University Press; 2006. Todas las figuras de este artículo han sido realizadas por los autores a partir de fotografías y representaciones de los originales, excepto, en la figura 15, como se hace constar.

5. D'Errico, Francesco. Palaeolithic origins of artificial memory systems: An evolutionary perspective. In: Renfrew, Colin; Scarre, Cris, eds. Cognition and material culture: the archaeology of symbolic storage. Cambridge: McDonald Institute; 1998, p. 19-50. D’Errico, Francesco et al. Archaeological evidence for the emergence of language, symbolism, and music. An alternative multidisciplinary perspective. Journal of World Prehistory. 2003; 17 (1): 1-70. 
La producción deliberada de marcas no se reconoce como tal por la mayoría de la comunidad científica hasta los hallazgos de la cueva sudafricana de Blombos, donde se encontraron unas incisiones geométricas en una pieza de ocre de más de 77.000 años de antigüedad (figura 2). Recientes hallazgos de la misma cueva ${ }^{6}$, nos hablan de manifestaciones similares con más de 100.000 años de antigüedad. Hay que tener en cuenta que para diversos autores estas marcas no serían arte; y aunque lo fueran, éste no sería figurativo, única manifestación verdaderamente convincente - según estos autores - de una mente realmente moderna. El debate está servido, y en cualquier caso parece ir quedando claro que la existencia de marcas deliberadas en diversos tipos de materiales se remonta a períodos muy antiguos.

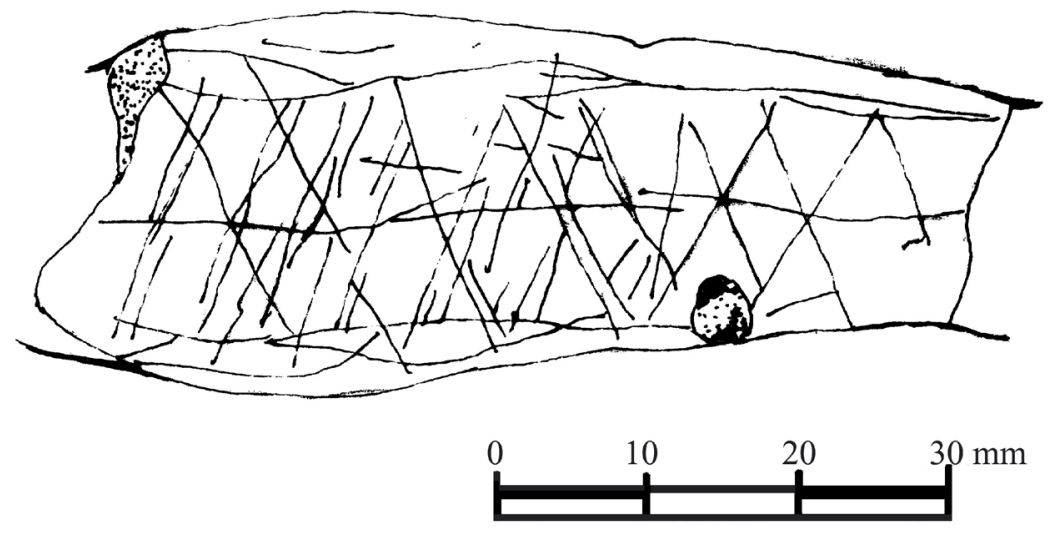

Figura 2. Grabados de Blombos I.

Los nuevos hallazgos de la cueva de Blombos han sido interpretados por algunos autores ${ }^{7}$ como las primeras manifestaciones de un tipo de registro muy probablemente simbólico y con una larga tradición (figura 3). No obstante, y según estos mismos autores, parece difícil considerarlos registros contables dada la difícil visibilidad de algunos de sus $\operatorname{trazos}^{8}$. En

\footnotetext{
6. Henshilwood; Christopher S.; D'Errico, Francesco; Watts, lan. Engraved ochres from the Middle Stone Age levels at Blombos Cave, South Africa. Journal of Human Evolution. 2009; 57: 27-47.

7. Henshilwood; D'Errico; Watts, n. 6.

8. Simplificamos la decoración de las figuras 2 y 3 a los trazos que se observan sin microscopio.
} 

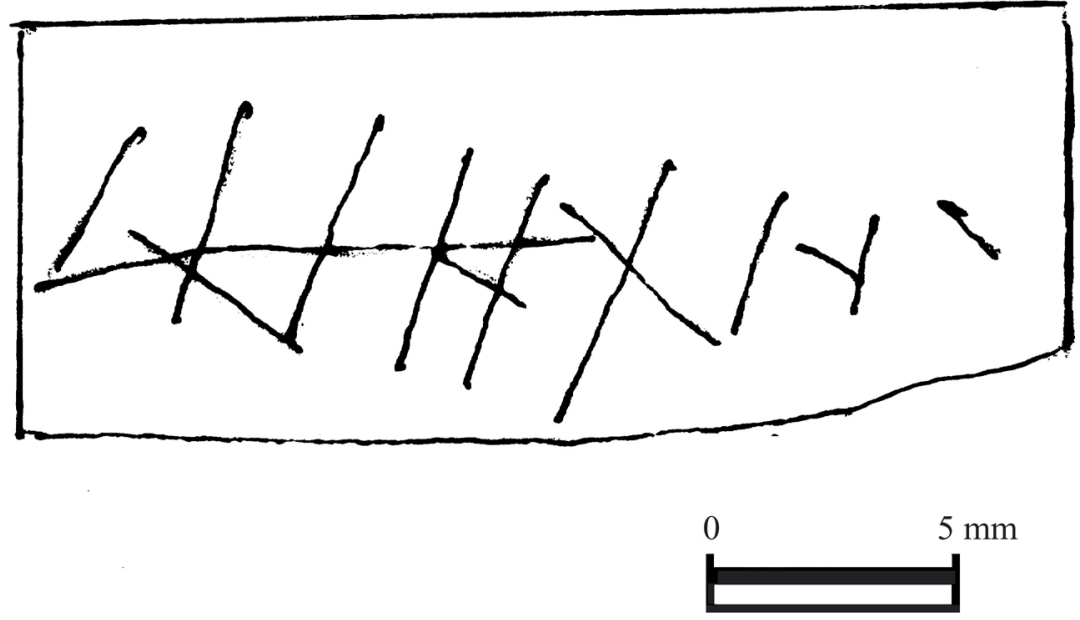

Figura 3. Grabados de Blombos II [simplificados].

este punto nos vamos a encontrar con un tema que es, de nuevo, relativamente controvertido.

Este sería un ejemplo de lo que apuntábamos: no todas las marcas deliberadas tienen por qué representar registros contables. De hecho, las marcas deliberadas en todo tipo de objetos son muy abundantes en el registro arqueológico de prácticamente todas las épocas, llegando incluso hasta nuestros días, y pueden haber sido hechas por multitud de motivos. Así, en muchos casos es posible que no sean más que un mero adorno, un motivo estético, a veces identificativo de un grupo.

Un conjunto de líneas paralelas, que a primera vista podría parecer un registro contable, puede tener un significado simbólico ajeno enteramente a un proceso de contabilidad. Es el caso, por ejemplo, de la cosmogonía reflejada en los motivos geométricos de los Zafimaniry de Madagascar; para ellos, un conjunto de líneas paralelas, utilizado muy frecuentemente en los productos de esta cultura, representa la rectitud que hay que seguir en la vida. En algunos casos, un conjunto de líneas más o menos paralelas pueden representar un alfabeto, como sería el caso del lenguaje oghámico ${ }^{9}$.

9. Graves, Robert. La diosa blanca. Madrid: Alianza; 1996. 
A este respecto, cabe mencionar también la estrecha relación y los paralelismos existentes entre verdaderos registros contables y los sistemas alfabéticos. La visión estándar actual sitúa el origen de la escritura en Mesopotamia. Esa visión está fundamentada en una continuidad desde los pictogramas hasta las formas que conocemos hoy en día, estando plenamente comprobados unos estadios intermedios de uso registrado de ideogramas que se concretan después en una escritura cuneiforme. Pero esa misma visión estándar se da en el origen escrito de lo que asumimos como registro matemático de esta civilización, basada en una continuidad análoga desde sistemas de numeración material, como los guijarros de barro sumerios o elamitas, a formas impresas, incisas o escritas sobre tablillas, que también conducirían a sistemas de numeración cuneiformes ${ }^{10}$.

Ahora bien, más allá del caso particular de las numeraciones mesopotámicas (en las que, además, encontramos un singular recurso a la base 60, de muy remota relación con la peculiaridad anatómica de los diez dedos que tenemos los primates entre las dos manos), la continuidad en el registro matemático que mejor queda atestiguada es más bien el tránsito desde el recurso a las muescas hasta los sistemas de numeración escritos; continuidad que podemos constatar en los primeros sistemas de numeración de la práctica totalidad de las antiguas civilizaciones: egipcios, minoicos, helenos pre-alfabéticos, chinos, pueblos itálicos (romanos, etruscos) e hindúes. Es muy probable, pues, que los primeros registros contables se dieran efectivamente en forma de muescas.

En algunos casos, incluso, estos sistemas han llegado hasta nuestros días sin apenas transformaciones formales, y está plenamente asumido por la comunidad científica internacional que constituyen casos innegables de registros contables. Este es el caso de las tarjas, tablillas de madera u otro material en las que se realizaban muescas para anotar y registrar cantidades referidas a objetos $\mathrm{u}$ otro tipo de unidades producto, generalmente, del intercambio, y que se han estado utilizando hasta el presente en numerosas regiones del mundo ${ }^{11}$. Así, diferentes tribus de bosquimanos del suroeste de África (Namibia) continúan utilizando hoy en día bastones-calendario de madera ${ }^{12}$. Los bosquimanos son considerados hoy día la tribu más

10. Ifrah, Georges. Historia universal de las cifras. Madrid: Espasa; 1997.

11. Flegg, Graham, ed. Numbers through the Ages. London: MacMillan Education Ltd; 1989.

12. Scarre, Chris. Timelines of the Ancient World. London: Dorling Kinderley; 1993. 
antigua del mundo desde el punto de vista genético ${ }^{13}$. En España, destaca el recurso a las tarjas hasta tiempos muy recientes, por ejemplo, en zonas de la provincia de Salamanca ${ }^{14}$, mientras en la historiografía se destaca el uso de tarjas por parte de la Oficina del Tesoro del Reino Unido hasta bien entrado el siglo XIX ${ }^{15}$.

Como vemos, algunos casos de muescas o marcas deliberadas sí serían manifestaciones evidentes de un registro contable. Sin embargo, también debe constatarse que esta afirmación no es válida para todos los materiales en los que existen muescas, grabados o dibujos. Por este motivo, creemos que hay que ser muy cautos a la hora de defender el uso contable de un hallazgo paleolítico. Sólo en aquellos casos en los que se observen determinadas combinaciones, agrupaciones o patrones específicos podremos afirmar con un cierto grado de verosimilitud que nos encontramos ante un registro contable y, por tanto, ante una huella fósil de un pensamiento matemático. Aplicando este criterio, observaremos que las primeras muestras relativamente evidentes de pensamiento matemático pertenecen a épocas más bien recientes de la historia de la humanidad, concretamente al Paleolítico superior (35.000-10.000 BP) o, a lo sumo, a épocas inmediatamente anteriores.

\section{Registro simbólico e historia de la matemática}

El historiador de la matemática indaga acerca de los registros contables plausibles que podrían constituir precedentes de las diferentes bases de numeración utilizadas: series repetidas de pares o tríos, marcas agrupadas de cinco en cinco o de diez en diez, etc.

Sin embargo, las colecciones de registros que más interés han presentado para el arqueólogo matemático han sido las que reúnen \pm 30 marcas. La razón inicial parece obvia, pues esta cantidad coincide prácticamente con el número de días $(29,5)$ del ciclo periódico natural utilizado como base para el cómputo del tiempo por nuestros predecesores:

13. Wells, Spencer. The journey of man: A genetic odyssey. New York: Random House; 2002.

14. Martín Gil, Francisco J. et al. Las tarjas. Un sistema primitivo de contabilidad. Investigación y Ciencia. 1997; 255: 39-40.

15. Flegg, n. 11. 
el mes lunar ${ }^{16}$. Por otro lado, los estudios de género más actuales animan a tener en cuenta, también, ese otro período cíclico natural ( \pm 28 días) del que adquiere conciencia empírica, al menos, la mitad de la población de nuestra especie que llega a edad adulta: el menstruo femenino, y que ha permitido adelantar que quizá los primeros matemáticos fueran mujeres: la conjetura Zaslavsky, por la historiadora de la matemática africana que la planteó ${ }^{17}$. Y es que, evidentemente, ambos ciclos, el lunar y el menstrual pueden prácticamente superponerse.

\subsection{La visión estándar en historia de la matemática}

La primera pieza a la que se han venido refiriendo los historiadores de la matemática ${ }^{18}$ es un hueso de lobo de unos 35.000 años, encontrado en Dolni Vestonice (Moravia, República Checa), donde también se descubrió una cabeza de mujer esculpida en marfil. En el hueso, de unos 18 centímetros de largo (figura 4), se encuentran 55 muescas. En la primera descripción presentada por Karl Absolom el 2 de octubre de 1937 en London Illustrated $^{19}$, las marcas se consideraban agrupadas de cinco en cinco y separadas por dos trazos intermedios más largos en dos series, una de $30(=6 \times 5)$ muescas, y otra de $25(=5 \times 5)$.

Las muescas sugieren el registro contable de una colección con ese mismo número de objetos, pero no existe tal supuesto agrupamiento de cinco en cinco, que sugeriría en el autor una posible correspondencia de

16. González Redondo, Francisco. A.; Silván Pobes, Enrique. Pensamiento simbólico y Matemática en el Paleolítico Superior. Boletín de la Sociedad Puig Adam. 2004; 68: 78-93.

17. Zaslavsky, Claudia. Africa counts: number and pattern in African culture. Boston: Prindle, Schmidt and Weber; 1973; Zaslavsky, Claudia. Women as the first mathematicians. Women in Mathematics Education Newsletter. 1991; 14 (1): 4; Zaslavsky, Claudia. Mathematics in Africa: Explicit and implicit. In: Grattan-Guinness, Ivor, ed. Companion Encyclopedia of the History and Philosophy of the Mathematical Sciences. London: Routledge; 1994, p. 85-92.

18. Véanse entre otros, Struick, Dirk. J. Stone Age mathematics. Scientific American. 1948; 179: 44-49; Seidenberg, Abraham. The ritual origin of counting. Archive for History of Exact Sciences. 1962; 2: 1-40; Boyer, Carl B. A History of Mathematics. New York: Wiley; 1968; Bunt, Lucas N. H.; Jones, Phillip S.; Bedient, Jack D. The historical roots of elementary mathematics. New Jersey: Prentice-Hall; 1976; Struick, Dirk J. A concise history of mathematics. New York: Dover; 1987; Eves, Howard. An introduction to the history of mathematics. Orlando (Florida): Saunders College Publishing; 1992.

19. El artículo se reproduce en Isis. 1938; 28: 462-463 y Flegg, n. 11, p. 37-38. 


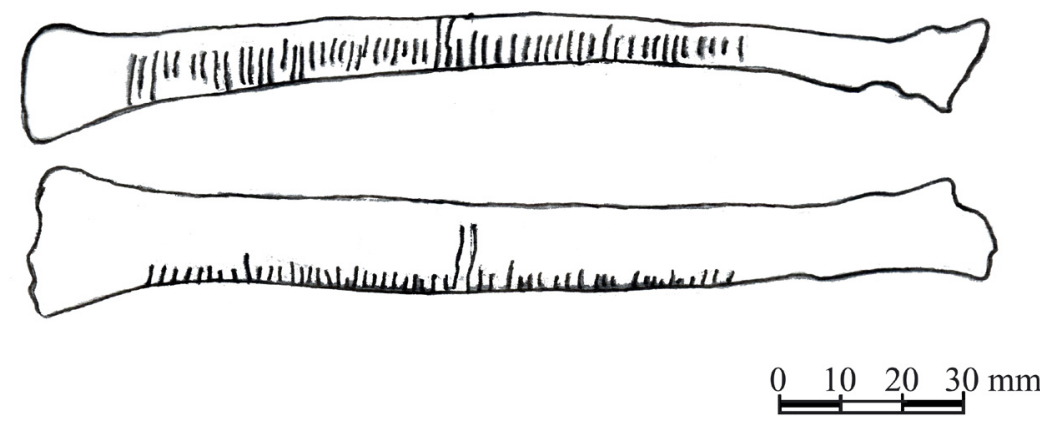

Figura 4. Hueso de Dolni Vestonice.

las marcas de cada grupo con los dedos de la mano. Siguiendo esa tentadora hipótesis sin contrastar, Ifrah ${ }^{20}$ supuso que las incisiones, además de agrupadas, estaban dispuestas en dos series paralelas a lo largo de dos caras del hueso, aunque más tarde Ifrah ${ }^{21}$ abandonó esa disquisición y rebajó la antigüedad del hueso a 20.000 años.

Los vestigios descubiertos de este tipo comienzan a ser abundantes, aunque la mayor parte siguen inéditos en la literatura. Así, en el British Museum de Londres ${ }^{22}$ se conserva una varilla ( $¿$ alfiler?) de hueso (figura 5), de hace unos 34.000 años, catalogada como procedente de Gorge d'Enfer (Abri Lartet, Dordogne, Francia), con incisiones análogas a las del hueso precedente $^{23}$. Tiene una longitud de 20 centímetros, y contiene muescas agrupadas en tres columnas, una frontal y dos laterales. Suponen, respectivamente (atendiendo a la separación entre las marcas de cada serie), $31(=8+8+10+5)$ en la cara central, $37(=9+2+8+3+4+5+8)$ en la columna de la derecha y $33(=3+8+5+2+10+5)$ en la de la izquierda, aunque quizá se hayan perdido por abrasión algunas marcas de la serie central en la cabeza de la pieza.

\footnotetext{
20. Ifrah, Georges. Las cifras. Historia de una gran invención. Madrid: Alianza; 1987.

21. Ifrah, n. 10.

22. Disponible en: http://www.britishmuseum.org/explore/highlights/highlight_objects/pe_prb/d/ decorated_bone_pin.aspx (fecha de actualización: 2001; citado febrero 2010).

23. Sieveking, Ann. A catalogue of Paleolithic art in the British Museum. London: The British Museum Press (no 151); 1987.
} 


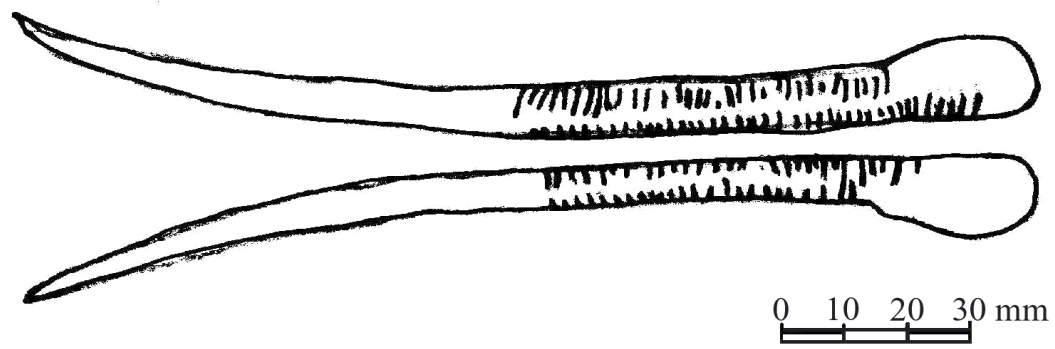

Figura 5. Varilla de Gorge d'Enfer.

Como antes, podrían aventurarse diferentes hipótesis acerca de los posibles contenidos matemáticos de la varilla más allá de las pretensiones meramente decorativas del autor. Pero para ello sería necesario estudiar la pieza directamente.

Realmente, el tipo y cantidad de materiales en los que indagar posibles manifestaciones simbólicas relacionadas con el registro de algunas cantidades empieza a ser notable. En la literatura ${ }^{24}$ sí se suele dar entrada a un asta de reno (figura 6), fechado hace unos 15.000 años, hallado en Brassempouy (Las Landas, Francia), y conservado en el Museo de Aquitania de Burdeos. En él se encuentran marcados 1, 3, 5, 7 y 9 trazos rectilíneos, en una disposición que ha dado lugar a no pocas conjeturas en lo que se refiere a las pretensiones matemáticas de su autor.

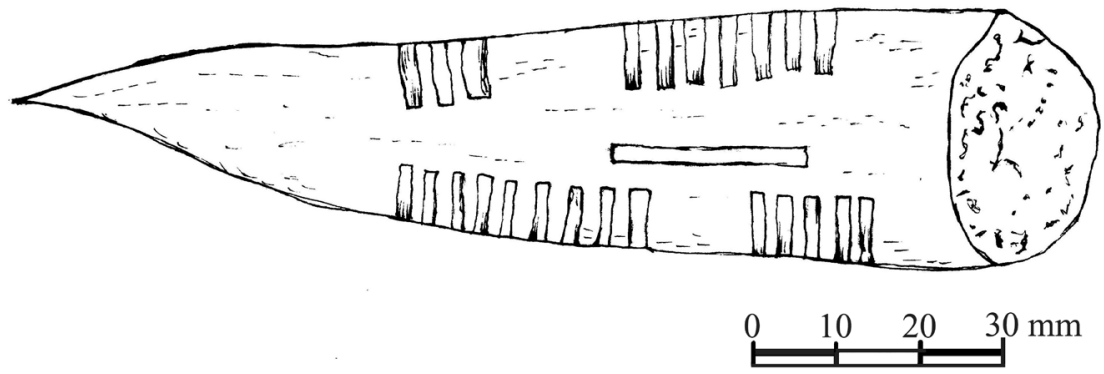

Figura 6. Asta de Brassempouy.

24. Ifrah, n. 10, p. 170-171. 
Así Ifrah, ha venido a considerarlo «una especie de "herramienta aritmética” que contiene una representación gráfica de los primeros números impares, así como una disposición que permite hallar rápidamente algunas propiedades elementales».

Estas propiedades elementales, partiendo de la situación $2 \times 2$ de las marcas y prescindiendo del posible valor 1 de la muesca horizontal,

$$
\left(\begin{array}{ll}
3 & 7 \\
9 & 5
\end{array}\right)
$$

serían, entre otras posibles, las siguientes:

$$
9-7=5-3=2 ; 3+9=5+7=12 ; 7-3=9-5=(9+5)-(7+3)=4 .
$$

Aunque plausibles, las interpretaciones de Ifrah no han podido ser demostradas aún. De hecho, se han encontrado otras piezas análogas, con marcas en otras disposiciones, en las que resulta más complicado detectar intenciones parecidas. Por ejemplo, en la placa de hueso de datación Auriñaciense (figura 7) encontrada en la ya citada Gorge d'Enfer, también se observan muescas en dos series transversales ${ }^{25}$. En la primera hilera aparecen separadas 5, 6 y 5 marcas; en la otra, 4 y 6 . Por tanto, y en la misma línea, habría que buscar correlaciones entre los números:

$$
\left(\begin{array}{lll}
5 & 6 & 5 \\
4 & 6
\end{array}\right)
$$

En la otra cara de la placa aparecen las marcas 6 y 4; 3, 8, 6 y 6, y las correlaciones habría que buscarlas en

$$
\left|\begin{array}{llll}
5 & 6 & 5 & \\
4 & 6 & 5 & \\
6 & 4 & 6 & \\
3 & 8 & 6 & 6
\end{array}\right|
$$

25. Marshack, Alexander. Lunar notation on Upper Paleolithic remains. Science. 1964; 146: 743-745; Marshack, Alexander. The roots of civilization. New York: Weidenfeld and Nicolson; 1972a, p. 50-55. (2a ed., 1991); Marshack, Alexander. Cognitive aspects of Upper Paleolithic engravings. Current Anthropology. 1972b; 13: 445-477. 


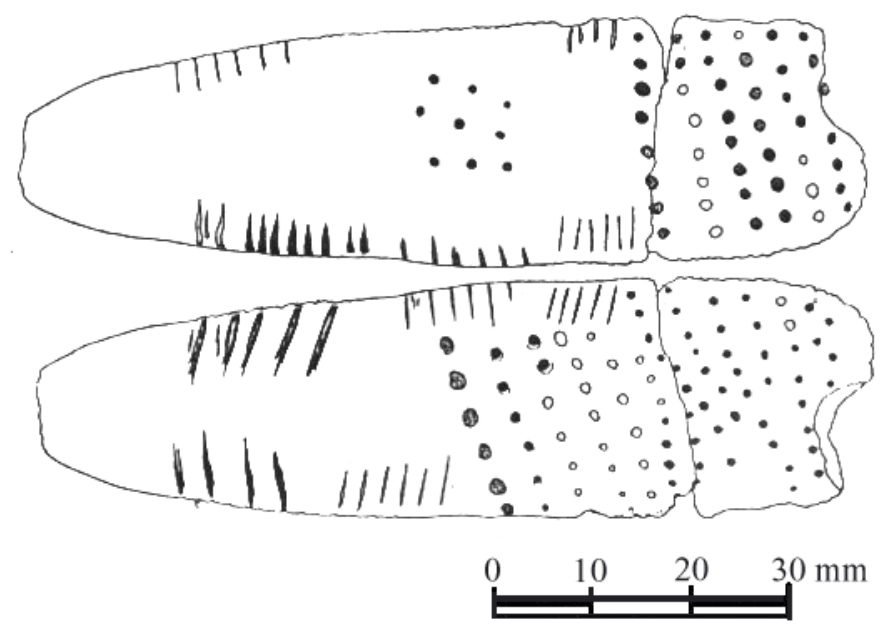

Figura 7. Placa de Gorge d'Enfer.

Pero en esta pieza no parece sencillo encontrar propiedades aritméticas tan sugerentes como en la precedente.

\subsection{Hacia el registro del tiempo: la cota Marshack}

Ciertamente, los diferentes grupos humanos del Paleolítico Superior pudieron sentir la necesidad de realizar registros contables de diferentes colecciones de objetos o sucesos. De entre estos últimos, uno debió ser, sin duda, el transcurrir del tiempo tomando como unidad el día, agrupándolos según meses lunares o, incluso, contemplando series temporales mucho más largas. Por supuesto, la certeza en la repetición constante en el tiempo de estos procesos pudo constituir una de las primeras motivaciones contables de nuestros antepasados ${ }^{26}$.

Una pieza a la que se está dando en los últimos tiempos cierta importancia es la Placa de Blanchard (figura 8), encontrada en Abri Blanchard (Francia). Está datada hace más de 25.000 años (Auriñaciense), y en ella se encuentran 69 marcas que han sido analizadas al microscopio, en sus 


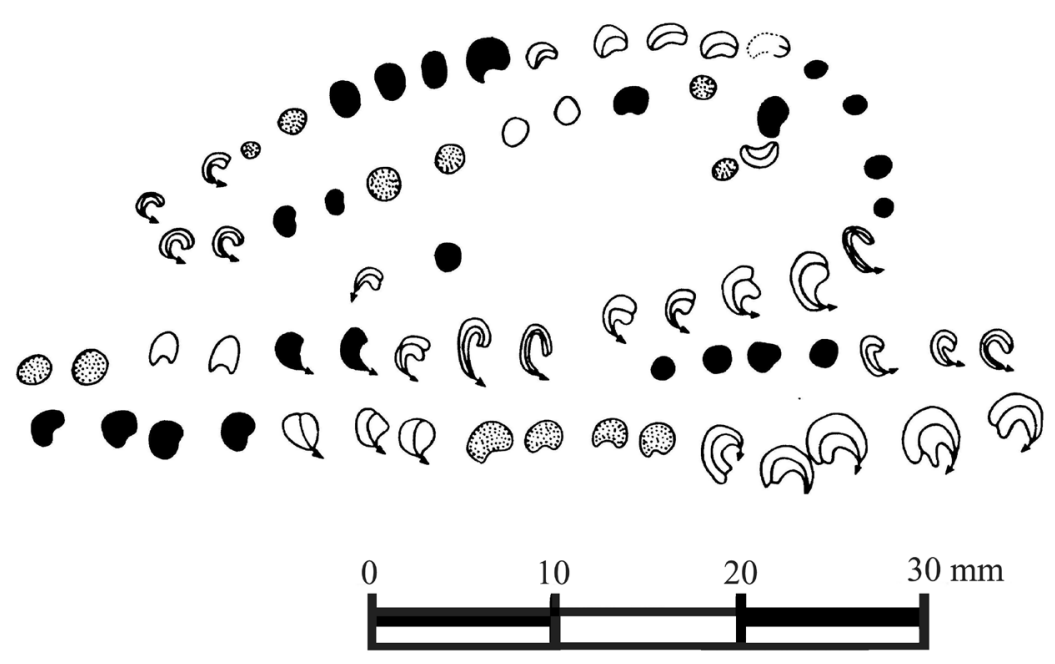

Figura 8. Marcas en la Placa de Blanchard [Marshack, 1972a].

formas, profundidades y tamaños, por Alexander Marshack ${ }^{27}$. GrattanGuinness ${ }^{28}$ asume la interpretación de Marshack, según la cual las incisiones en el hueso corresponderían al paso de la luna, día a día, por sus diferentes fases durante ese período de 69 días: llena, media, creciente y nueva. Esta interpretación correspondería a la que denominamos la cota Marshack, por el autor que más lejos ha llevado las aptitudes matemáticas de nuestros antepasados paleolíticos.

Por otro lado, el hallazgo en la cueva de Tai (Francia) de otra placa de hueso, de unos $9 \mathrm{~cm}$ de longitud y datada hace unos 12.000 años, con casi 2.000 incisiones en su superficie desarrolladas en diferentes filas (algunas incompletas), en algunos casos con agrupaciones de unas 29 marcas, ha llevado a Marshack a conjeturar que podría tratarse del registro de los días de diferentes años sucesivos. Se trataría, por tanto, del calendario solar más antiguo conocido ${ }^{29}$. Aunque será difícil descubrir realmente por qué

27. Marshack, n. 25, 1972a, p. 45-50; Jègues-Wolkiewiez, Chantal. Aux raciness de l'astronomie, ou I'ordre cache d'une oeuvre paléolithique. Antiquités Nationales. 2005; 37: 43-52.

28. Grattan-Guinness, Ivor. The rainbow of mathematics. A history of the mathematical sciences. New York: Norton; 2000, p. 24.

29. Marshack, Alexander. The Tai Plaque and calendrical notation in the Upper Paleolithic. Archaeological Journal. 1991; 1 (1): 31. 
su autor las realizó, el carácter no decorativo de las marcas podría apoyar la hipótesis del registro cuantitativo frente a interpretaciones meramente artísticas.

\subsection{Contabilidad en el Paleolítico africano: la conjetura Zaslavsky}

Ahora bien, nuestros antepasados no desarrollaron estas habilidades solamente en Europa, y los pre-historiadores, aunque sigan imbuidos del usual etnocentrismo cultural occidental, ya no pueden estudiar únicamente las manifestaciones simbólicas descubiertas entre los Urales y la cornisa cantábrica.

Las piezas de ocre de la Cueva de Blombos que veíamos antes han llevado a autores como d'Errico et al. ${ }^{30}$ a concluir que «las habilidades cognitivas modernas surgieron gradualmente en África en conjunción con los cambios biológicos que marcan el origen de nuestra especie». De hecho, los diseños abstractos grabados de Blombos pueden considerarse entre las primeras manifestaciones de esa habilidad cognitiva que supone registrar conceptos con la ayuda de elementos materiales.

La comunidad científica internacional tiene asumido que en África comenzaron a utilizarse instrumentos para contar desde hace 37.000 años ${ }^{31}$. De entre estas piezas destaca el Hueso de Lebombo (figura 9); un peroné de babuino con 29 incisiones paralelas hallado, junto con otros trozos de madera y hueso grabados, en la Cueva de Border, en las montañas Lebombo

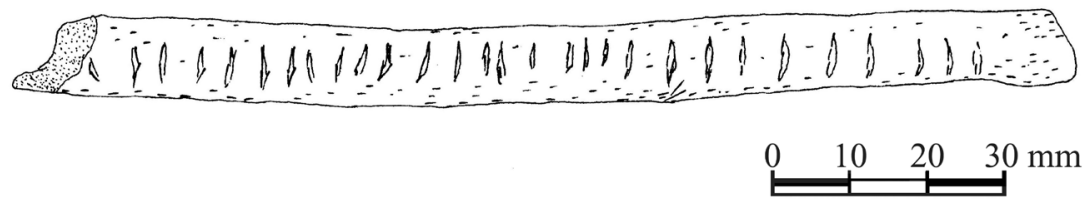

Figura 9. Hueso de Lebombo.

30. D’Errico et al., n. 5, p. 15-19.

31. Cain, Chester R. Implications of the marked artifacts of the Middle Stone Age of Africa. Current Anthropology. 2006; 47 (4): 675-681. 
entre Sudáfrica y Swazilandia ${ }^{32}$, y que podría ser más antiguo ${ }^{33}$. El hueso está fracturado, y no se sabe si originalmente tenía 29 ó 30 muescas (en el hueso completo no cabrían más incisiones); pero, en cualquier caso, es plausible su relación con el cómputo de días del mes lunar.

En la frontera entre la República Democrática del Congo y Uganda, a las orillas del Lago Edward (una de las fuentes del Nilo), hace más de 8.500 años vivió durante unos pocos siglos una comunidad de pescadores y recolectores, cuyo hábitat quedó posteriormente enterrado por una erupción volcánica. Aunque por las fechas el asentamiento correspondería ya al período Mesolítico, Brooks et al. ${ }^{34}$ retrasan su antigüedad hasta hace 25.000 años, ya sí propiamente Paleolítico Superior.

Entre los restos que se han encontrado de este grupo ${ }^{35}$, destaca un hueso de 10,2 cm de largo (figura 10), con una pieza de cuarzo insertada en uno de los extremos (quizá para poder dibujar marcas sobre piedra con ella), conocido como Hueso de Ishango, expuesto en una instalación monográfica destacada y contextualizada en el Museum des Sciences Naturelles de Bruselas.
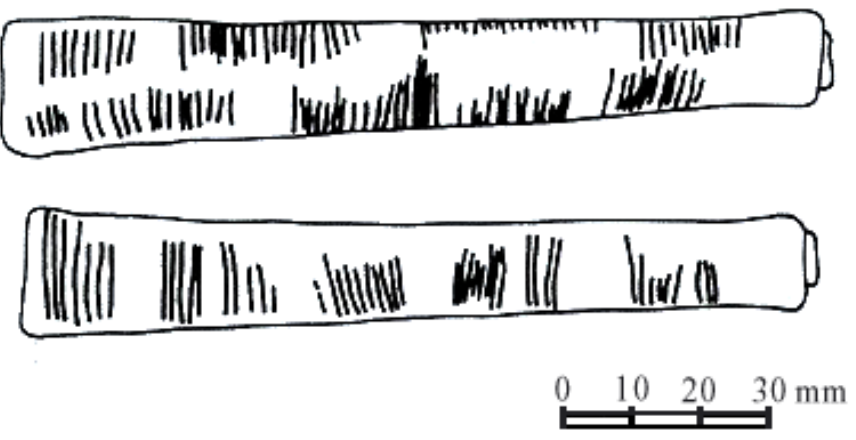

Figura 10. Hueso de Ishango.

\footnotetext{
32. Bogoshi, Jonas; Naidoo, Kevin; Webb, John. The oldest mathematical artefact. Mathematical Gazette. 1987; 71 (458): 294.

33. Brooks, Alison S. et al. Dating and context of three Middle Stone Age sites with bone points in the upper Semliki Valley, Zaire. Science. 1995; 268: 548-553.

34. Brooks, Alison S.; Smith, Catherine C. Ishango revisited. New age determinations and cultural interpretations. African Archaeological Review. 1987; 5: 65-78.

35. De Heinzelin, Jean. Ishango. Scientific American. 1962; 206 (6): 105-116.
} 
Tiene 168 incisiones transversales dispuestas en diferentes agrupaciones, separadas entre sí, a lo largo de tres columnas. Desarrollando en el plano la superficie cilíndrica del hueso, en la primera columna de la izquierda vemos 11, 13, 17 y 19 muescas. En la columna central aparecen 3, 6, 4, 8, 10, 5, 5 y 7 marcas. Finalmente, en la columna de la derecha observamos $11,21,19$ y 9 muescas.

Esta última, de acuerdo con De Heinzelin ${ }^{36}$, proporcionaría indicios del primer uso de un sistema de numeración de base diez, pues las agrupaciones son de $11(=10+1), 21(=20+1), 19(=20-1)$, y $9(=10-1)$. Además, las marcas de la tercera columna suman 60 , igual que las de la izquierda, en la que encontramos cantidades de muescas que se corresponden con los cuatro números primos entre 10 y 20 (11, 13, 17 y 19). Incluso se ha creído encontrar en la columna central una posible ilustración del método de duplicación (usual en la matemática egipcia miles de años más tarde), pues junto a las 3 primeras muescas aparecen $6(=3 \times 2)$; a continuación de las siguientes 4 vemos $8(=4 \times 2)$; y tras las $10(=5+5)$ que siguen aparecen 5,5 y 7 trazos.

Junto a la evidencia de que la suma de las marcas en las tres columnas (respectivamente, 60, 48 y 60) es siempre múltiplo de 12, Marshack aventuraba que podría contener la tabla de números primos más antigua conservada, y que el autor pretendía representar un calendario lunar de seis meses ${ }^{37}$. Zaslavsky ${ }^{38}$ incluso llegó a conjeturar que podría tratarse del recuento de ciclos menstruales, por lo que el hueso sería obra de una mujer, preguntándose si no serían mujeres las primeras matemáticas de la historia.

Junto con el éxito socio-científico que supone la disposición expositiva en el Museo de Bruselas donde se conserva la pieza, y las numerosas páginas web que se le dedican ${ }^{39}$, también destaca su presencia, para ilustrar los posibles primeros estadios matemáticos de la humanidad, en numerosas historias de la disciplina ${ }^{40}$.

\footnotetext{
36. Fauvel, John; Grey, Jeremy, eds. The history of mathematics. A Reader. London: MacMillan; 1987, p. 5-6.

37. Marshack, 1972a, n. 25, p. 31.

38. Zaslavsky, 1991, n. 17.

39. Puede verse la pieza en 3D en: http://www.naturalsciences.be/expo/old_ishango/en/ishango/ introduction.html (fecha de actualización 2001; citado febrero 2010).

40. Véanse entre otros, Flegg, n. 11, p. 38-39; Eves, 1992, n. 18, p. 10.
} 


\subsection{Matemática implícita en el mobiliar europeo}

El propósito o finalidad matemática de los autores de las piezas analizadas probablemente permanecerá siempre en el ámbito de la conjetura plausible. Pero estas personas pertenecían a nuestra misma especie y demostraron a lo largo de los años, con sus pinturas parietales y sus grabados mobiliares, una gran capacidad de simbolización, por lo que debemos aportar algunas pruebas más que ilustren la indudable mente matemática de nuestros antepasados paleolíticos fuera del ámbito de lo opinable; pruebas no recogidas aún por los historiadores de la matemática en sus manuales.

Así, destaca una placa ovoide de hueso de unos 15 centímetros de largo (figura 11), catalogada como bramadera o churinga, encontrada en la Cueva de la Roche (Lalinde, Francia), perteneciente al Magdaleniense Superior (hace 13.500-12.000 años), y depositada en el Musée des Antiquités Nationales de Saint-Germain-en-Laye de París (Francia). Sin discutir si el autor pretendió fabricar realmente un instrumento musical destinado a zumbar al girarlo con una cuerda, sí podemos analizar la disposición rítmica de sus marcas.

La pieza se fabricó mediante pulido buscando una completa simetría básica, concretada después decorando la superficie siguiendo dos ejes, uno longitudinal y otro transversal, según un sistema de notación mixto basado en agrupaciones de muescas de 5 en 5 y de 10 en 10 que, dada su uniforme distribución, debía tener pre-decidida mentalmente nuestro antepasado antes de empezar la tarea.

Aunque es imposible precisar el orden en el que se fueron realizando las marcas, la primera serie que observamos son nueve grupos de 5 trazos, 5 horizontales y 5 verticales, alternativamente ortogonales entre sí, a lo

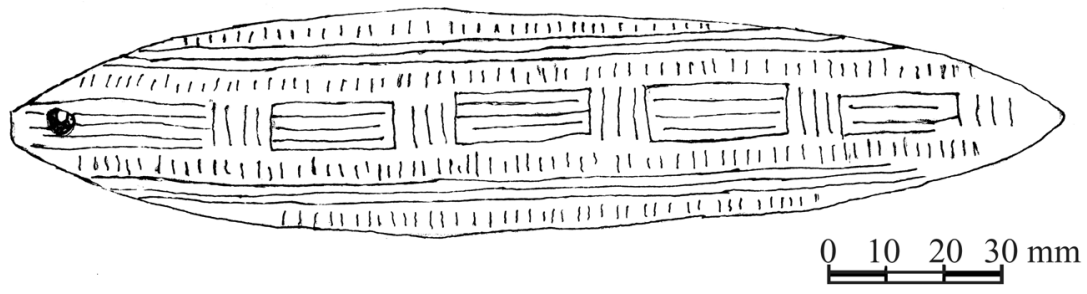

Figura 11. Bramadera de La Roche. 
largo del eje longitudinal. Quedarían determinados cinco rectángulos de base casi tres veces la altura, separados entre sí por otros 3 trazos verticales paralelos (3, número de rectángulos centrales de la pieza). En un extremo del eje encontramos el agujero para colgar la pieza, quedando completado, en el extremo opuesto, por 4 nuevas marcas verticales.

Seguidamente, y simétricos con respecto a ese mismo eje, encontramos dos series, de $\approx 62$ trazos más pequeños cada una, distribuidos a ambos lados del diseño longitudinal, cada una de las cuales puede pensarse que reúne grupos de $10+3+10+3+10+3+10+3+10$ coordinadamente con el diseño inicial, 10 a lo largo de las bases de cada rectángulo y 3 como continuación de los 3 trazos verticales intercalados entre cada dos de ellos.

Para completar la decoración se incluyeron seguidamente, a cada lado del eje, tres líneas paralelas a éste y otra serie de pequeños trazos, alineados también en paralelo con los grupos análogos de 62 marcas anteriores, hasta completar los límites de la pieza.

Verdaderamente, la persona que realizó esta bramadera, además de tener una notable percepción espacial, sabía contar. Presumiblemente lo hacía con una idea primitiva de lo que sería un sistema decimal que utiliza el 5 (y quizá el 3) como base auxiliar, motivado, sin duda, por el que Aristóteles consideraba el accidente anatómico de tener cinco dedos en cada mano.

Este sistema, el usual a medida que los diferentes pueblos fueron alcanzando sus respectivos niveles de civilización, es el que, con la notación conveniente y la concepción posicional concebida en la India, se utiliza hoy en día.

\section{El registro del pensamiento matemático en el mobiliar de la región franco-cantábrica}

Precisamente, la abundancia de piezas de arte mobiliar en la región franco-cantábrica (desde el Périgord hasta Asturias), proporciona piezas extraordinarias que merecerían ser consideradas en todo tratado acerca de la prehistoria de la matemática, con similar e incluso superior impor- 
tancia que las piezas tan destacadas mundialmente como las ya analizadas. Esta abundancia ha llevado a numerosos arqueólogos a aportar estudios profundos sobre las modalidades de registro del pensamiento simbólico, las distintas técnicas, los diferentes soportes, para situar los materiales con plausible registro matemático ${ }^{41}$. Y es que, en el arte rupestre: 1) se buscan figuras animales y humanas, fácilmente discernibles; 2) se estudia la decoración considerada geométrica, muy visual; pero 3) resulta mucho más compleja la interpretación de las marcas (muescas, incisiones) que acompañan a unas $\mathrm{y} / \mathrm{u}$ otras.

Dos son los grandes modos de plasmación de los temas del arte mobiliar, la figurativa (por las figuras representadas, en general de animales), y la no figurativa o abstracta. Esta última se encuentra desde el Gravetiense al Aziliense, con un momento de esplendor en el Magdaleniense final.

El problema de interpretar el significado del arte paleolítico es complejo, pues no resulta fácil acercarse a la mente de sus autores, ni discernir los códigos gráficos que empleaban. Lo que sí parece admitido es que eran unos códigos comunes que se referían a unos mismos conceptos desde los Urales hasta la Península Ibérica ${ }^{42}$, prácticamente un lenguaje común ${ }^{43}$. Nuestros antepasados del Gravetiense al Magdaleniense repiten una serie limitada de signos, figurativos o no. Representaban lo que el grupo reconocía y admitía, sin grandes variaciones que pudieran confundir a los interlocutores: sus capacidades creativas se restringían a un código inteligible, sin cambios sustanciales, mantenido durante varios miles de años. Los expertos en el tema ${ }^{44}$ consideran que el conjunto del

41. Véanse entre otros, Leroi-Gourhan, Andre. Préhistoire de l'art occidental. París: Mazenod; 1965; Leroi-Gourhan, Andre. Les signes parietaux du Paléolithique supérieur franco-cantábrico. Symposium Internacional de Arte rupestre. Barcelona; 1968, p. 67-79; Rosenfeld, Andrée. Review of notation dans les graveurs du Paléolithique supérieur. Antiquity. 1972; 36: 317-319; Barandiarán Maestu, Ignacio. Arte mueble del Paleolítico cantábrico. Universidad de Zaragoza. Monografías Arqueológicas XIV; 1973; Corchón Rodríguez, Ma Soledad. El arte mueble paleolítico cantábrico: contexto y análisis interno. Madrid, Centro de Investigaciones y Museo de Altamira; 1986.

42. Balbín Behrmann, Rodrigo. Los cazadores de la Cantabria glacial y su expresión gráfica. In: Arias, Pablo; Ontañón, Roberto, eds. La materia del lenguaje prehistórico. El arte mueble paleolítico de Cantabria en su contexto. Santander, Gobierno de Cantabria; 2004, p. 23-36.

43. Corchón Rodríguez, Ma Soledad. Europa 16500-14000 a.C.: un lenguaje común. In: Arias, Ontañón, eds., n. 42, p. 105-126.

44. Por ejemplo Balbín, n. 42, p. 25. 
arte paleolítico es un sistema gráfico constituido por unos «pocos signos que se componen y organizan de distinta manera, sobre la misma base, y que representan conceptos a través de la organización propia de un lenguaje escrito», abstracciones que parten de algo conocido y que conocen y entienden los miembros del grupo.

Frolov ${ }^{45}$, además de la presencia de cantidades de \pm 30 muescas, destaca en el mobiliar europeo algunas secuencias aritméticas especiales, concretadas en las cifras 5 y 7 o sus múltiplos 10 y 14, y la ordenación de las incisiones en las piezas en ritmos binarios y ternarios, conjeturando diferentes modelos astronómicos (año solar, meses lunares) que vincula con ritmos biológicos de la naturaleza como ciclos estacionales, períodos de gestación del ser humano, etc. Corchón ${ }^{46}$ destaca la reiterada aparición de incisiones seriadas en paralelo en agrupamientos basados en el 5, 7, 10 y 20 o en secuencias de 27 a 30 muescas en series continuas, aunque siguiendo a Leroi-Gourhan ${ }^{47}$ atribuye a los agrupamientos el carácter de apoyo rítmico a una recitación en el marco de una tradición oral que desconocemos por completo, siendo esta visión la más extendida entre los prehistoriadores.

También existen numerosas piezas con series de 12 y 13 incisiones. $Y$ es que no debemos olvidar que un año (astronómico, cinegético) tiene una duración de 365 días y 1/4, es decir, algo más de 12 meses lunares $(29,5 \times 12=354)$ y algo menos de 13 lunaciones $(29,5 \times 13=383,5)$; mientras que, atendiendo al otro período cíclico destacado (el menstrual), 28x13=364, es decir, prácticamente un año.

Estos registros matemáticos tendrían su origen en el Solutrense y se presentan en diferentes soportes como placas, azagayas o arpones. Sin embargo, las piezas mobiliares que tienen un carácter simbólico más especial ${ }^{48}$ son los colgantes. Para Corchón las incisiones en paralelo en los bordes de las piezas (lo que considera el «motivo decorativo 1» en su clasificación de la decoración no figurativa), que alcanzan su máximo desarrollo en la época

\footnotetext{
45. Frolov, Boris A. Aspects mathematiques dans l'art prehistorique. Valmonica Symposium, Actes du Symposium Internacional d'Art Prehistorique. Capo di Ponte: Ed. Del Centro; 1970, p. 475-478.

46. Corchón, n. 41, p. 233.

47. Leroi-Gourhan, André. El gesto y la palabra. Caracas, Universidad Central de Venezuela; 1971.

48. Arias; Ontañón, eds. n. 42, p. 46.
} 
Graveto-Solutrense ${ }^{49}$, «se aplican con especial asiduidad en un determinado tipo de objetos, los colgantes, que contribuyen a caracterizar» ${ }^{50}$.

Así, el Colgante de Enfer (figura 12), de unos 30.000 años, encontrado en Gorge d'Enfer (Dordogne, Francia) junto con la varilla que describíamos antes (expuesto también en el British Museum), presenta muescas en paralelo en sus bordes (más una tercera serie frontal con pequeño número de marcas) que se interrumpen por la rotura de la pieza tanto en la cabeza

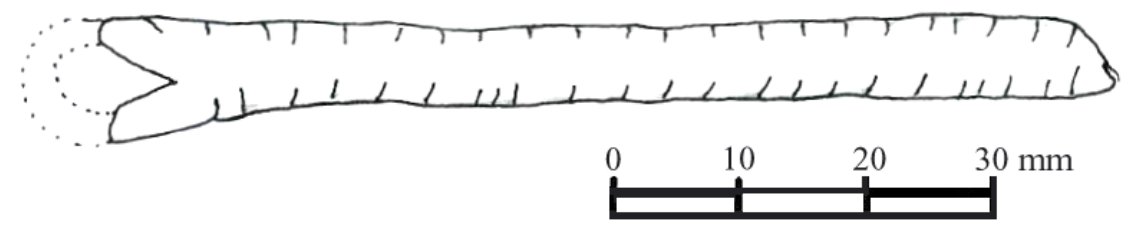

Figura 12. Colgante de Gorge d'Enfer.

de colgadura como en la parte inferior. En total, la pieza completa podría presentar unas 60 incisiones.

El Colgante de Morín (Cantabria) (figura 13), realizado en piedra y de sección oval, pertenece al Gravetiense (Auriñaciense superior), y está roto en la parte correspondiente a la perforación ${ }^{51}$. Con unas dimensiones

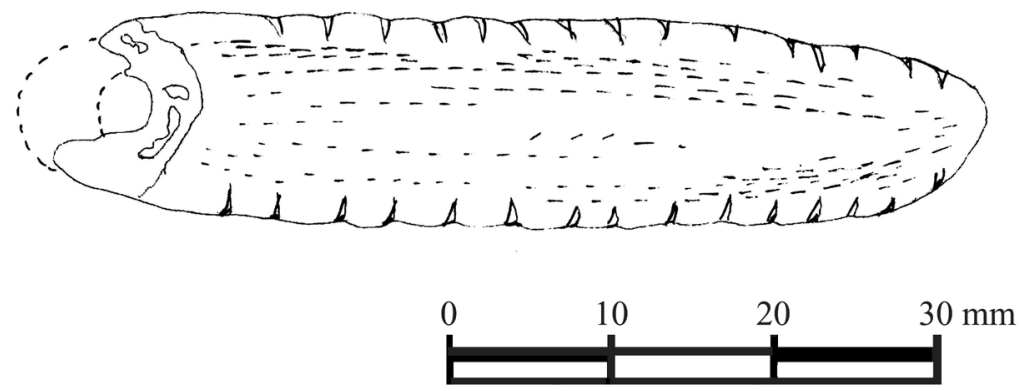

Figura 13. Colgante de Morín.

49. Corchón, n. 43, p. 116.

50. Álvarez Fernández, Esteban. Los objetos de adorno-colgantes del Paleolítico Superior y del Mesolítico en la Cornisa Cantábrica y en el Valle del Ebro: una visión europea. Salamanca, Ediciones Universidad de Salamanca; 2006.

51. Corchón, n. 41, p. 254-255. 
de $9 \mathrm{~mm} \times 40 \mathrm{~mm}$, está grabado con una serie armónica de \pm 30 muescas transversales en paralelo, contorneando el objeto ${ }^{52}$.

El «estrato F» de La Garma A (Cantabria), correspondiente al Gravetiense (21000 BP), ha proporcionado un singular colgante confeccionado a partir de un metacarpo de cabra. La parte que se conserva mide $11,5 \mathrm{~cm}$ de largo, 3 de ancho y 2 de diámetro (figura 14). Presenta una perforación oval central, y en sus dos caras está decorado con incisiones transversales, finas y cortas, reunidas longitudinalmente en diferentes agrupaciones. De acuerdo con Álvarez Fernández ${ }^{53}$, en la cara palmar pueden contarse 15 incisiones en el borde derecho y otras 15 en el borde izquierdo. En la cara

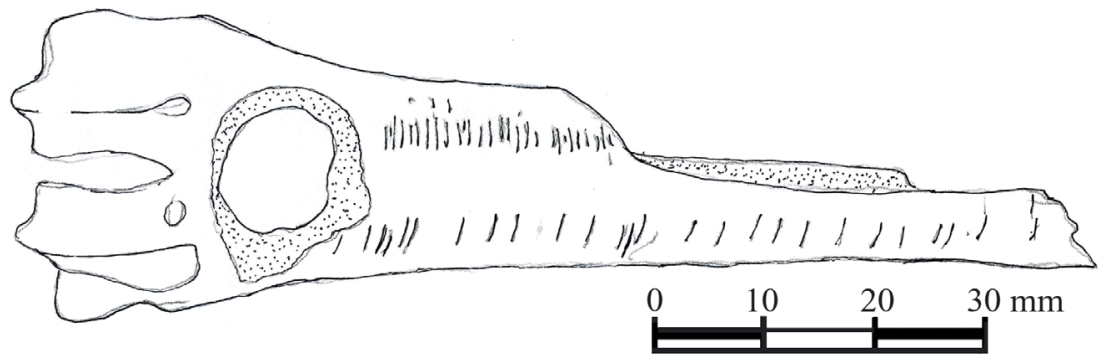

Figura 14. Metacarpo de La Garma.

dorsal, dividida longitudinalmente por un surco central, se localizarían 30 incisiones a la derecha, y otras 15 a la izquierda.

Los Colgantes de Las Caldas (Solutrense superior), proceden de la cueva de Las Caldas (Asturias). Son fragmentos de marfil inciso, y aunque no se conserva la perforación en ninguno de los dos, Corchón ${ }^{54}$ los cataloga como colgantes (figura 15) ${ }^{55}$. Tienen unas dimensiones análogas de 25 $\mathrm{mm}$ de ancho por 66 de alto, la mayor de ellas, y $23 \mathrm{~mm}$ por 54 la menor, aunque no se encontraron juntos, sino con una separación de $10 \mathrm{~cm}$ en el nivel 8 de la Sala 1 de la cueva. Ambos fueron recortados de la misma

52. En Álvarez Fernández, n. 50, p. 232, hay dos vistas frontales y dos laterales, apreciándose 29 incisiones.

53. Álvarez Fernández, Esteban. Cat. № 79. Metápodo perforado con series de líneas incisas. In: Arias, Ontañón, eds., n. 42, p. 218

54. Corchón, n. 41, p. 259.

55. Para Álvarez Fernández, n. 50, p. 267-268, la segunda pieza habría tenido una perforación en la parte dañada. 

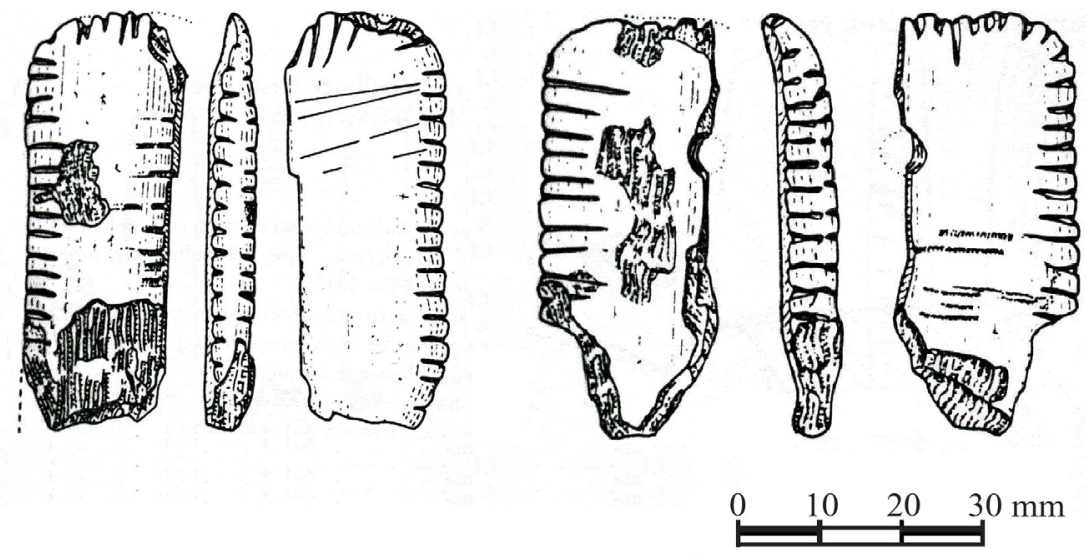

Figura 15. Colgantes de Las Caldas. Fuente: Corchón, n. 41.

manera y están decorados con marcas paralelas en los bordes. Las series están espaciadas regularmente, contorneando el objeto y, en las zonas no dañadas, se agrupan en series de \pm 15 incisiones.

Colgantes con decoración no figurativa encontramos en otras piezas posteriores halladas en La Garma A (Cantabria) ${ }^{56}$ : dos caninos atróficos de ciervo perforados en la zona central de la raíz ${ }^{57}$. Presentan el mismo tipo de muescas horizontales, cortas y paralelas, aunque algunas de ellas se han perdido al romperse ambos dientes tras ser decorados. El primero (figura 16a), localizado en el estrato K (Magdaleniense Inferior), conserva 24 de las \pm 30 incisiones que inicialmente pudieron hacerse en todo el contorno.

En el segundo (figura 16b), correspondiente al estrato L (Magdaleniense Medio), todavía pueden verse en las zonas no dañadas 25 incisiones, 21 en el borde y 4 en la cara lingual. ¿Habría 4-5 más en las zonas dañadas de ambos colgantes?

En Las Caldas también se encontraron cuatro incisivos de caballo, recogidos a escasa distancia entre ellos, en la base del Magdaleniense medio.

56. Ontañón Peredo, Roberto, coord. La Garma. Un descenso al pasado. Santander: Gobierno de Cantabria; 2001.

57. Álvarez Fernández, Esteban. Cat. № 58. Colgante; Cat. № 73. Colgante. In: Arias; Ontañón, eds., n. 42 , p. 204 y 214. 

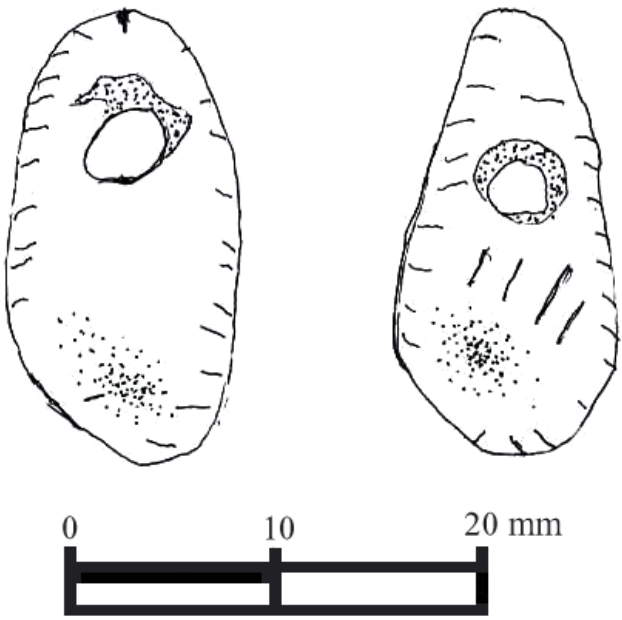

Figura 16. Colgante K y Colgante L de La Garma.

Según Corchón ${ }^{58}$, uno está perforado y muestra $30(11+13+6)$ incisiones cortas en los bordes; otro está doblemente perforado, pero no presenta ninguna marca; un tercero, que no está perforado, ofrece 10 incisiones en el borde y dos series de cuatro ángulos (o $2 \times 4=8$ muescas) embutidos en una cara y 3 ángulos (o 2x3=6 muescas más) embutidos en la cara opuesta; el cuarto no presenta muescas ni perforación.

En suma, en los hallazgos arqueológicos en la región cantábrica, desde el Gravetiense y a lo largo del Magdaleniense, puede destacarse:

1) Numerosas piezas, que han sido perforadas para ser ensartadas en colgantes, presentan decoración mediante incisiones cortas, horizontales y paralelas, del mismo tipo que los historiadores de la matemática consideran manifestaciones primigenias de registro contable.

2) En la mayoría de los casos, el análisis de la decoración permite con$\operatorname{tar} \pm 30$ muescas. Normalmente (en los caninos y las piezas pequeñas de hueso) en agrupaciones conjuntas; pero también (en piezas más grandes) en colecciones de $15+15$.

58. Corchón, n. 43, p. 122. Corchón Rodríguez, Ma Soledad. Cat. № 40. Diente aguzado con grabados geométricos. In: Arias; Ontañón, eds., n. 42, p. 197. 
3) Nuevas valoraciones deben seguir corroborando y/o matizando el modelo de notaciones lunares planteado por Marshack ${ }^{59}$.

4) Debe trascenderse la interpretación clásica de la notación simbólica de las piezas destacadas como, simplemente, «marcas de caza» ${ }^{60}$.

\section{Altamira: culminación en el registro mobiliar del pensamiento ma- temático}

Las consideraciones precedentes constituyen el marco contextual del aspecto nuclear y más importante de este trabajo: la presentación, en el ámbito histórico-matemático, de cuatro piezas (figura 17) de arte mobiliar (originalmente pudieron existir más, hoy perdidas) halladas juntas en la Cueva de Altamira durante las excavaciones de 1924 y 1925. Intentaremos mostrar cómo, desde otras perspectivas disciplinares, complementarias de las usuales entre los prehistoriadores ${ }^{61}$, estas piezas pueden recibir una nueva valoración para la historia del pensamiento matemático, ya que son probablemente la primera muestra aparente, a nivel del registro arqueológico mundial, de una recursividad simbólica. La recursividad es una propiedad que, según algunos autores, hace único y exclusivo al lenguaje humano ${ }^{62}$. Las cuatro piezas de las que hablamos serían, por tanto, un hallazgo único y singular, de gran relevancia para la historia y la prehistoria de la mente de nuestra especie y que, por consiguiente, merecerían una ubicación destacada e individualizada (y contextualizada) en cualquier museo que las exhiba; en este caso, el Museo de Altamira.

Inicialmente catalogadas como plaquitas de marfil ${ }^{63}$, hoy se sabe que están elaboradas sobre hueso hioides de caballo. Muy planas, con un grosor de menos de $2 \mathrm{~mm}$, tienen unas dimensiones de entre 14 y $16 \mathrm{~mm}$ de ancho

59. Robinson, Judith E. Not counting on Marshack: A reassessment of the work of Alexander Marshack on notation in the Upper Palaeolithic. Journal of Mediterranean Studies. 1992; 1: $1-16$.

60. Álvarez Fernández, Esteban. Cat. № 15. Diente aguzado decorado con cabeza de caballo; Cat. No 117. Colgante. In: Arias; Ontañón, eds., n. 42, p. 180 y 234.

61. Álvarez Fernández, n. 50.

62. Hauser, Marc D.; Chomsky, Noam; Fitch, W. Tecumseh. The faculty of language: What is it, who has it, and how did it evolve? Science. 2002; 298: 1569-1579.

63. Breuil, Henri; Obermaier, Hugo. La cueva de Altamira en Santillana del Mar. Junta de las Cuevas de Altamira-Hispanic Society of America-Academia de la Historia; 1935. 

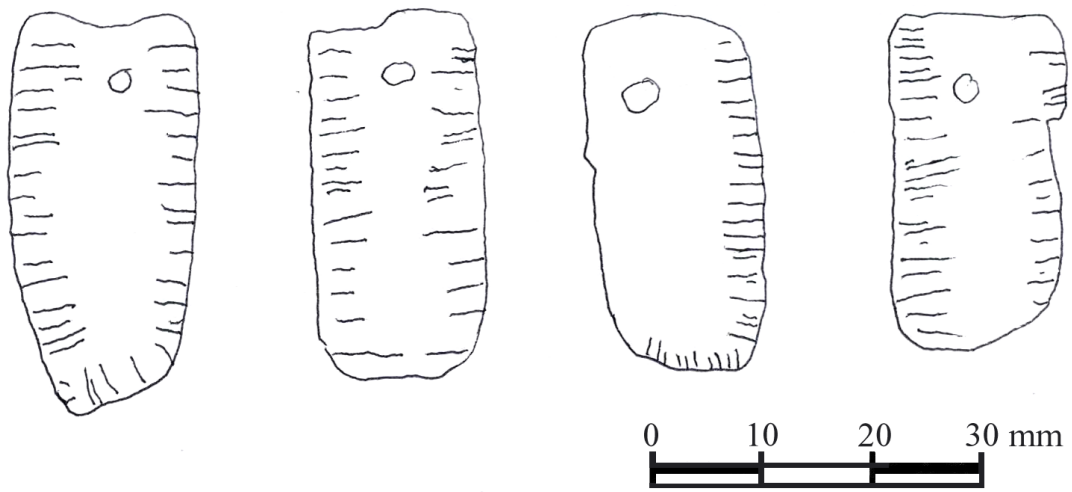

Figura 17. Colgantes de Altamira.

y entre 31 y $36,5 \mathrm{~mm}$ de alto ${ }^{64}$. A todas se les dio una forma prácticamente rectangular (una es un poco más grande y curvada) y fueron perforadas en uno de los extremos, probablemente para ensartarlas conjuntamente en un colgante único para adorno personal ${ }^{65}$. Cada una de ellas presenta, a lo largo de los bordes de su cara superior, el mismo tipo de incisiones: muescas cortas, transversales y paralelas; dos de ellas, además, presentan el mismo tipo de decoración en la cara inferior. Por su datación, Solutrense superior-final, serían unos 5.000 años anteriores a la época en que se pintó el gran techo de los polícromos ${ }^{66}$.

Aunque las piezas están bastante deterioradas, todas y cada una de las cuatro están decoradas de manera análoga, y por la información que proporciona su estado actual, en ellas se podrían haber contabilizado en torno a 30 incisiones, dependiendo de la consideración que se le quiera dar a las diferentes marcas, pues no todas tienen la misma profundidad, longitud o anchura, y en alguna de las caras la erosión ha borrado parte de las muescas.

Desde su descubrimiento, diferentes autores han presentados breves reseñas descriptivas. Así, para Breuil y Obermaier, quienes las estudian

\footnotetext{
64. Para Breuil y Obermaier, n. 63, p. 197, medían 15-16 mm de ancho y 40-45 mm de alto.

65. Lasheras, José A; De las Heras, Carmen. De qué viven y cómo viven (segunda parte). In: Los Indios de América del Norte en el siglo XVIII. Madrid: Fundación Santillana; 1992, p. 83.

66. González Sainz, César. El Magdaleniense Superior-final de la región cantábrica. Santander: Tantín-Universidad de Cantabria, 1989.
} 
dentro de la industria ósea encontrada en el nivel Solutrense de la cueva, se trata de cuatro plaquitas de marfil, subrectangulares en las que el borde estaría decorado con pequeñas estrías marginales, constituyendo, para ellos, los objetos de adorno más notables del yacimiento. Corchón ${ }^{67}$ considera que presentan «marcas irregulares de longitud desigual, en su mayoría dispuestas transversalmente al eje mayor del colgante y agrupadas en series continuas y completas, probablemente rítmicas» ${ }^{6}$.

Finalmente, en la descripción que puede observarse en la vitrina de título Solutrense Superior (18.500 años) del Museo de Altamira, simplemente se considera que son un conjunto de colgantes en hueso hioides de caballo englobados, sin destacar en modo alguno, como número 7 dentro de un conjunto de 11 piezas de dicho período (raspadores, perforadores, buriles, azagayas, etc.). Sin embargo, y desde el punto de vista del análisis del registro material del pensamiento simbólico, pueden apuntarse otras notas caracterizadoras que no hemos encontrado destacadas hasta el presente y que, sin embargo, convierten a estas cuatro plaquitas en un fenómeno singular.

La importancia del número de muescas realizadas en cada pieza $( \pm 30)$, como destacábamos anteriormente, se debe a su coincidencia con el número de días $(29,5)$ del mes lunar, así como con el del menstruo femenino $( \pm 28$ días). La persona que realizó las piezas determinó la misma decoración para todas ellas, repitió el mismo motivo, lo que exige tanto un recuento de los trazos realizados, como una correspondencia uno a uno entre los cuatro grupos de \pm 30 trazos. Frente a los hallazgos de piezas aisladas, con incisiones cortas perpendiculares al contorno, destacadas en los párrafos anteriores, nos encontramos ante la que probablemente sea la primera (y, hasta donde conocemos, única) colección, concebida como unidad de expresión simbólica ${ }^{69}$, constituida por (al menos) cuatro colgantes con este tipo de registro ${ }^{70}$.

Esta colección podría, pues, interpretarse como una unidad, aún estando constituida, a su vez, por (al menos) otras cuatro unidades (cada una de las plaquitas). Estas unidades constituyentes de aquella unidad

\footnotetext{
67. Corchón, n. 41, p. 116 y 266-267.

68. Ver, también, Barandiarán, n. 41, p. 72 y Lámina 43; y, Álvarez Fernández, n. 50, p. 262-263.

69. D'Errico, n. 5.

70. Los también solutrenses Colgantes de Las Caldas (figura 15), son sólo dos y no conservan la posible perforación para suspenderlos.
} 
superior poseerían relaciones entre ellas (todas mostrarían la contabilidad de un mismo fenómeno), siendo la relación entre ellas el nuevo concepto que aquí se está representando. Dicho de otra manera, este conjunto de plaquitas sería la representación de la repetición de un ciclo o, lo que es lo mismo, la ciclicidad de un ciclo. Un ejemplo gráfico de esto lo constituye la propia interpretación que podríamos dar a estas plaquitas: una entidad - el año, ¿un embarazo? - constituida de unidades cíclicas menores - los meses. Se representarían, así, dos conceptos: uno de manera tangible (el mes, cada una de las plaquitas) y un concepto jerárquicamente superior y representado de manera totalmente inmaterial, mediante las relaciones entre las plaquitas.

Frente a las piezas anteriores, la representación del ciclo que constituye este conjunto de plaquitas, cada una representando un ciclo de orden inferior, estaba únicamente en la mente de quien las realizó; como está en la mente de quien se aproxime ahora a estas plaquitas mediatizada por esta interpretación. No hay soporte material para el concepto que da unidad a las plaquitas, es meramente mental.

La ciclicidad representada de manera abstracta (no material) por el conjunto de estas plaquitas, sería un caso evidente de recursividad. Se entiende por ésta la introducción de elementos o entidades dentro de otros elementos o entidades de categoría similar, y parece ser una característica exclusiva y definitoria de nuestro lenguaje ${ }^{71}$, característica que podría no haber aparecido en nuestra especie hasta tiempos tan recientes como el Paleolítico Superior ${ }^{72}$. Gracias a esta capacidad de combinatoria abstracta de nuestro lenguaje y, por tanto, de nuestra mente, podemos construir y entender oraciones sintácticamente complejas (como «El periodista que fue agredido por el político y estuvo hospitalizado ha recibido un premio»), donde varios mensajes completos (el periodista fue agredido por un político; el periodista estuvo hospitalizado) están contenidos dentro de otro mensaje completo y jerárquicamente superior (el periodista recibió un premio). Con independencia del fenómeno concreto que estas cuatro piezas de Altamira pudieran estar representando (sean meses dentro del año u otra cosa), constituirían como conjunto la primera manifestación simbólica de

71. Hauser, Chomsky, Fitch, n. 62; Makuuchi, Michiru et al. Segregating the core computational faculty of human language from working memory. Proceedings of the National Academy of Sciences (USA). 2009 (en prensa).

72. Coolidge; Wynn, n. 1. 
la recursividad como característica de la mente humana mediatizada por el lenguaje, al existir un símbolo (quizá el año) que, sin soporte material, habría servido de concepto-guía de orden jerárquicamente superior para la construcción de la colección de plaquitas.

Dejando por tanto al margen la mera finalidad artística que le han atribuido hasta ahora los prehistoriadores más autorizados, aventuramos aquí la hipótesis de que se trata de un grupo de meses lunares, análogos a los que algunos de los más reputados historiadores de la matemática han atribuido a muchos de los hallazgos individuales destacados anteriormente. El hecho de que sean sólo cuatro las plaquitas que se conservan podría estar en contra de nuestra interpretación de esta colección como representación de un ciclo anual. Evidentemente, la colección podría haber estado compuesta originalmente de un número mayor de placas. Pero incluso aunque no hubiera sido éste el caso, la colección podría estar representando la repetición de ciclos de orden inferior dentro de un ciclo de orden superior, aunque sólo fuera un ciclo parcial que, a su vez, pudiera estar perteneciendo a otro ciclo superior, como las estaciones dentro del año solar.

Caben otras posibles interpretaciones, evidentemente, como que se trate del cómputo de ciclos menstruales agrupados dentro de otra entidad de orden superior, como podía ser la duración de un embarazo a partir de la constatación de la primera falta. Pero aceptando una u otra posibilidad, $\mathrm{y}$ ante el hecho incontestable de que no se trata de una pieza aislada, sino de un conjunto de al menos cuatro piezas recortadas a partir de hueso hioides, grabadas sistemática y sucesivamente, que conforman una unidad, su importancia nos lleva a proponer, desde estas páginas, que esta colección tan singular ocupe el lugar que se merece dentro de los manuales de historia de la matemática, de historia y prehistoria de la mente humana, que se publiquen en adelante. En suma, estas piezas deberían tener una consideración de al menos el mismo nivel que disfrutan mundialmente muchas de las piezas revisadas en los apartados anteriores. 
